\title{
ANALISA NPSH KERUSAKAN IMPELLER POMPA CETRIFUGAL CAIRAN $\mathrm{CH}_{3} \mathrm{OH}$
}

\author{
Rosmiati $^{1}$, Tayeb Ibrahim ${ }^{2}$, Masykur $^{3}$ \\ 1)Jurusan Teknik Mesin Universitas Trunajaya Bontang \\ ${ }^{2)}$ Jurusan Teknik Mesin Universitas Trunajaya Bontang \\ ${ }^{3)}$ Jurusan Teknik Mesin Universitas Teuku Umar \\ ${ }^{1)}$ hanafi.rosmiati@gmail.com \\ 2)taiyeb.ibrahimm@gmail.com \\ ${ }^{3)}$ masykur@utu.ac.id
}

\begin{abstract}
ABSTRAK
Prilaku zat cair selalu dipengaruhi oleh lingkungan sekitar berupa temperatur dan tekanan (termodinamika). Temperatur dan tekanan ini mempengaruhi sifat perubahan phasa cair menjadi campuran air dan uap atau sebaliknya. Pompa yang berfungsi untuk mengalirkan zat cair juga mempunyai temperatur dan tekanan. Jika tekanan turun dan temperatur tetap ataupun naik pada pompa maka terjadi perubahan phase cair menjadi phase campuran cair dan uap. Perubahan phase ini di dalam pompa (sisi isap) dinamakan phenomenon capitation. Kapitasi dalam pompa akan menimbulkan erosi part casing maupun impller sehingga terjadi penurunan performance. Penelitian ini menganalisa terjadinya erosi pada impeller pada pompa 040G01S PT. KMI dari sudut phenomenon capitation. Penomena terjadinya kapitasi dalam suction pompa secara empiris dapat diketahui jika nilai NPSHa yang dibutuhkan kurang atau sama dengan Nilai NPSHr yang tersedia atau NPSHa $\leqq$ NPSHr. Nilai NPSHa dipengaruhi oleh konfigurasi installasi perpipaan pompa sisi isap (suction). Untuk mengetahui penyebab terjadinya erosi pada casing dan impeller maka perlu dilakuan perhitungan NPSH (Net Positive Section Head) dibutuhkan dan yang tersedian (manufaktur). Hasil penelitian ini nilai NPSHa $=4,75 \mathrm{~m}$ dan nilai $\mathrm{NPSHr}=5 \mathrm{~m}$ ) atau NPSHa $\leqq N P S H r$ pada level tangki $<45 \%$. Sehingga perlu dilakukan modifikasi installasi perpipaan sisi isap pompa.
\end{abstract}

Kata kunci: Kapitasi, NPSHa dan NPSHr

\section{ABSTRACT}

Liquid behavior is always influenced by the environment in the form of temperature and pressure (thermodynamics). This temperature and pressure affect the nature of the change in liquid phase into a mixture of water and steam or vice versa. Pumps that function to drain liquid also have temperature and pressure. If the pressure drops and the temperature stays or rises at the pump, the liquid phase changes to a liquid and vapor mixture phase. This phase change in the pump (suction side) is called the phenomenon capitation. Capitation in the pump will cause erosion of the impellers parts, resulting in decreased performance. This study analyzes the erosion of the casing and impeller at the 040-G01S pump of PT. KMI from the point of phenomenon of capitation. The phenomenon of capitation in pump suction empirically can be known if the required NPSHa value is less or equal to the available NPSHr value or NPSHa $\leqq N P S H r$. The NPSHa value is affected by the suction pump installation configuration. To find out the cause of erosion on the casing and impeller, it is necessary to calculate the NPSH (Net Positive Section Head) required and those available (manufacturers). The results of this study NPSHa value $=4.75 \mathrm{~m}$ and NPSHr value $=5 \mathrm{~m}$ ) or NPSHa $\leqq N P S H r$ at tank level $<45 \%$. So it is necessary to modify the installation of the pump suction side piping.

Keywords: Capitation, NPSHa and NPSHr 


\section{PENDAHULUAN}

Salah satu aset penting dunia industri proses dalam pembuatan suatu produk adalah pompa. Pompa ini digunakan untuk menyalurkan cairan, gas, maupun padatan untuk diproses lebih lanjut sehingga menghasilkan produk akhir sesuai dengan capasitas target yang telah ditetapkan tiap tahun oleh pemangku kepentigan (stakeholder). Untuk mencapai target ini maka setiap aset/equipment yang dikelola harus dapat bekerja sesuai dengan harapan diatas.

PT. KMI penghasil methanol mengoperasikan pompa centrifugal untuk menyalurkan hasil produksi akhir untuk disimpan ke tangki dan selanjutnya diangkut melalui jaringan pipa maupun angkutan kapal laut ke konsumen. Dalam pengoperasiannya pompa centrifugal mengalami kerusakan pada salah satu part penting yaitu impeller berupa cacat erosi sehingga menurunkan kemampuan pompa. Adanya kasus ini, maka perlu dilakukan analisa penyebab terjadinya erosi pada impeller untuk selanjutnya dilakukan tindakan koreksi agar tidak terjadi lagi dikemudian hari.

Seperti yang dilaporkan oleh Rahman fakultas Teknik Mesin USU dalam jurnal ISSN, EDinamis, Vol. 1-1, 2012 bahwa salah penyebab terjadinya erosi pada casing dan impeller adalah terjadinya kapitasi pada line suction pompa. Dengan melihat fenomina ini maka penulis menganalisa terjadinya erosi pada impeller pompa methanol dari sudut pandang terjadinya erosi impeller sebagai akibat terjadinya kapitasi dalam suction pompa methanol.

\subsection{Tinjauan Pustaka}

\subsubsection{Capitation}

Kapitasi adalah: Suatu proses terbentuknya uap dan pecahnya gelembung-gelembung uap didalam suction pompa tepatnya didaerah sudu impeller (pada umumnya). Hal ini terjadi akibat penurunan tekanan kondisi standar pada temperatur tetap pada suatu cairan sehingga mengalami perubahan phase cair ke uap pada kondisi dibawah tekanan saturasi cairan. Dengan adanya perubahan phase tersebut menimbulkan gelembung-gelembung uap pada cairan seperti yang terjadi jika kita memanaskan air diceret. Gelembung-gelembung uap ini akan pecah dan menghantam permukaan metal yang ada disekelilingnya secara terus menerus terjadi erosi.

Indikasi fenomena kapitasi yang terjadi pada pompa yang sedang running dapat dideteksi secara panca indra yaitu dengan mendengar kebisingan pada casing pompa seperti suara ketika seseorang memukul mukul pelan bolol berisi setengah "suara gelitik secara continue". Suara ini berbeda dengan suara pompa beroperasi secara normal.

\subsubsection{NPSH (Net Positive Suction Head)}

NPSH adalah kebutuhan tekanan spesifik (head, satuan meter atau feed) minimum pompa untuk bekerja secara normal pada sisi isap (suction) pompa. Nilai NPSH pada suction pompa digunakan untuk menilai apakah instalasi sistem perpipaan sisi suction pompa terjadi kapitasi atau tidak. Dimana fenomena kapitasi bersifat merusak impeller pompa. Agar tidak terjadi kapitasi maka nilai NPSH yang tersedia harus lebih besar atau sama dengan NPSH yang diperlukan:

$$
\mathrm{NPSHa} \geqq \mathrm{NPSHr}
$$

\subsubsection{NPSH yang tersedia (NPSHa)}

NPSHa yang tersedia adalah besarnya energi netto (head) yang tersedia pada instalasi penampang melintang jalan masuk cairan pada pompa (suction), besarannya dapat dihitung:

$$
\begin{aligned}
& \text { NPSHa }=Z e+\frac{P e+P b-P D}{\rho \cdot g}+\frac{V e^{2}}{2 g}-H v s \\
& \text { Atau Ze } \geqq N P S H a+H v s-\frac{P e+P b-P D}{\rho \cdot g}-\frac{V e^{2}}{2 g}
\end{aligned}
$$

Penjelasan konotasi parameter NPSH digambarkan dalam neraca energi (head), gbr. 1 . 


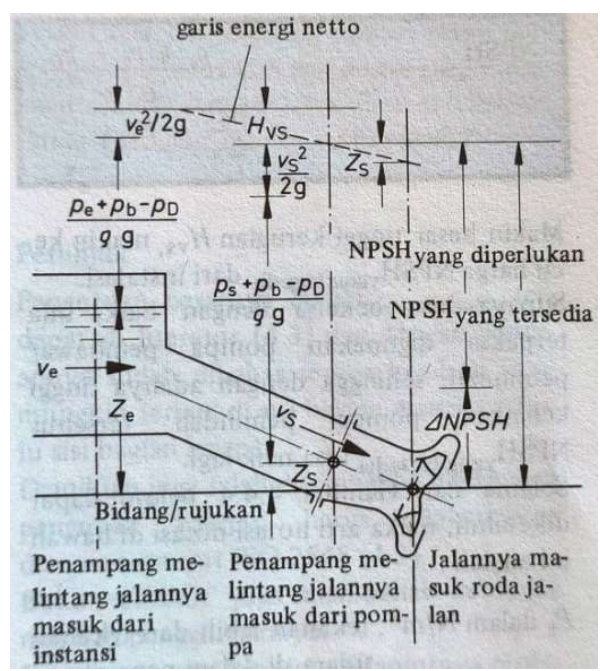

Gambar 1. Neraca energi untuk menentukan harga NPSH. Fritz Dietzel, 1987.

Arti konotasi pada gambar 1 dan persamaan (1), (2) dan (3)

$P_{\mathrm{e}}$ : Tekanan yang menyangkut bentuk penampung air reservoir tertutup atau terbuka, $\left(\mathrm{N} / \mathrm{m}^{2}\right)$

$\mathrm{P}_{\mathrm{b}}$ : Tekanan udara barometer, $(\mathrm{N} / \mathrm{m} 2)$

PD: Tekanan penguapan zat cair pada temperatur cairan (N/m2)

Ve: Kecepatan aliran pada sisi masuk pompa $(\mathrm{m} / \mathrm{s})$

$\rho$ : Massa jenis cairan $\left(\mathrm{kg} / \mathrm{m}^{3}\right)$

$\mathrm{H}_{\mathrm{vs}}$ : Head loss major + minor disepanjang saluran sisi masuk pompa (m)

G : Grafitasi 9,81 (m/s2)

Ze : Head static total $(\mathrm{m})$

\subsubsection{NPSH Required (NPSHr)}

NPSHr adalah besaran energi netto (head) yang dibutuhkan pompa (suction), besarannya diukur ditempat pengujian pompa (pabrik) dan dutulis pada name plate pompa bersama dengan data putaran permenit, debit Q, Head dan lain-lain. Karakteristik NPSHr pompa sentrifugal tergantung pada fungsi debit yang mengalir $\mathrm{m}^{3} / \mathrm{s} f(\mathrm{Q})$, atau dengan kata lain jika debit yang mengalir tidak konstan maka nilai NPSHr dapat digunakan pendekatan:

$$
\mathrm{NPSHr}=(0,3 \text { sampai } 0,5) \mathrm{n} \sqrt{Q}
$$

Dimana, Q berlaku untuk 0,1 sampai $1\left(\mathrm{~m}^{3} / \mathrm{s}\right)$ dan putaran impeller $\mathrm{n}=10$ sampai $50(\mathrm{rps})$

\subsubsection{Head loss Major}

Head loss major adalah kerugian tekanan (head) akibat faktor gesekan cairan yang mengalir di dalam pipa. Bentuk umum persamaan yang paling banyak digunakan untuk menghitung kehilangan tekanan dalam pipa/head loss dikenal sebagai persamaan Darcy-Weisbach yang diberikan oleh:

$$
\mathrm{h}_{\mathrm{fL}}=f \frac{L}{D}+\frac{v^{2}}{2 g}
$$

di mana, $\mathrm{f}$ : koefisen gesek, $\mathrm{L}$ : panjang total pipa (m), D : diamater dalam pipa (m),

$$
\mathrm{f}=64 / \mathrm{Re} \text { (laminar dan pipe roughness) }
$$

Sedangkan untuk jenis alira turbulen nilai koefisien gesek (f) menggunakan diagram Moody, seperti pada gambar 2 . 


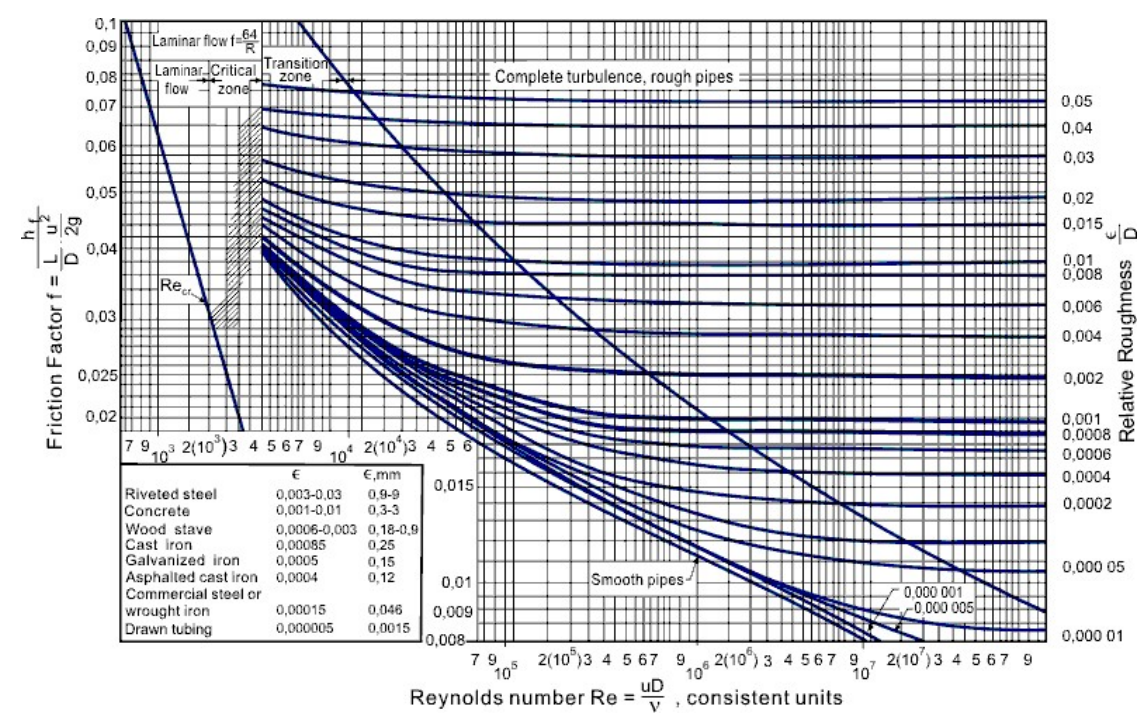

Gambar 2. Diagram friction factor for any kind and size of pipe (Fluid mechanics for engineering Tech.) \& Moody diagram. Sumber: Adapted from Streeter V.L. et. al. (1985) with

Dan Re adalah bilangan Reynolds number, permission.

$$
\operatorname{Re}=\frac{D v p}{\mu}
$$

$v:$ velocity $(\mathrm{m} / \mathrm{s}), \rho:$ Density $\left(\mathrm{kg} / \mathrm{m}^{3}\right)$ dan $\mu:$ viscocity kinematic $\left(\mathrm{N} . \mathrm{s} / \mathrm{m}^{2}\right)$

$\operatorname{Re}=<2000 \rightarrow$ Laminar dan $\mathrm{Re}=>2000 \rightarrow$ Turbulent

\subsubsection{Head Loss Minor}

Head loss minor adalah kerugian gesek yang terjadi pada aliran masuk fluida ke dalam pipa (inlet), aliran keluar fluida dari pipa (outlet), sambungan pipa/ fitting atau sambungan pipa tanpa fitting/ butt fusion, dan yang terakhir katup/ valve.

$$
\mathrm{h}_{\mathrm{fm}}=\Sigma \mathrm{k} \frac{v^{2}}{2 g}
$$

di mana $\Sigma k$ : total faktor gesek inlet, outlet, fitting dan valve

\subsubsection{Head Loss Total}

Head loss total $\left(\mathrm{H}_{\mathrm{vs}}\right)$ adalah total kerugian tekanan (head) head loss major di tambah head loss minor.

$$
\mathrm{H}_{\mathrm{vs}}=\mathrm{h}_{\mathrm{fL}}+\mathrm{h}_{\mathrm{fm}}
$$

\subsection{Penelitian}

\section{METODE PENELITIA}

Dalam penelitian ini menggunakan metode Applied research (Creswell, 2004), Empirical (Sangadji dan Sopiah, 2010), Case and field study (Sangadji dan Sopiah, 2010) dan survey dengan melihat langsung objek penelitian, mengumpulkan data-data teknis dan foto kemudian dilakukan pengolahan data-data teknis secara empiris berdasarkan refrensi buku dan jurnal internasional yang relevan.

\subsection{Tempat dan Waktu}

Penelitian ini dilakukan di PT. KMI selama 1 minggu tanggal 12 Nov - 18 Nov 2019.

\subsection{Subjek Penelitian}

Subjek penelitian adalah pompa methanol $040-\mathrm{G} 01 \mathrm{~S}$, jenis cetrifugal dengan spesifikasi teknis, tabel 1. 
Tabel 1. Spesifikasi teknis pompa

\begin{tabular}{|l|l|l|l|}
\hline Manufactur & $:$ Sulzer Weise & Temp Op. & $: 40^{\circ} \mathrm{C}$ \\
\hline Type & $:$ Cetrifugal pump/ZA 150-2200 & $\rho$ Methanol & $: 774 \mathrm{~kg} / \mathrm{m} 3$ \\
\hline Head & $: 35,5 \mathrm{~m}$ & $\mathrm{P}$ & $: 26,6 \mathrm{~kW}$ \\
\hline Ser. No. & $: 95664 / 2-1996$ & NPSHr & $: 5 \mathrm{~m}$ \\
\hline Q & $: 280 \mathrm{~m}^{3} / \mathrm{h}$ & $\mathrm{n}$ & $: 2950 \mathrm{rpm}$ \\
\hline $\mathrm{n}$ & $: 2950 \mathrm{RPM}$ & Stage & $:$ single \\
\hline
\end{tabular}

Sumber: Name plate pompa 040-G01S, 2019
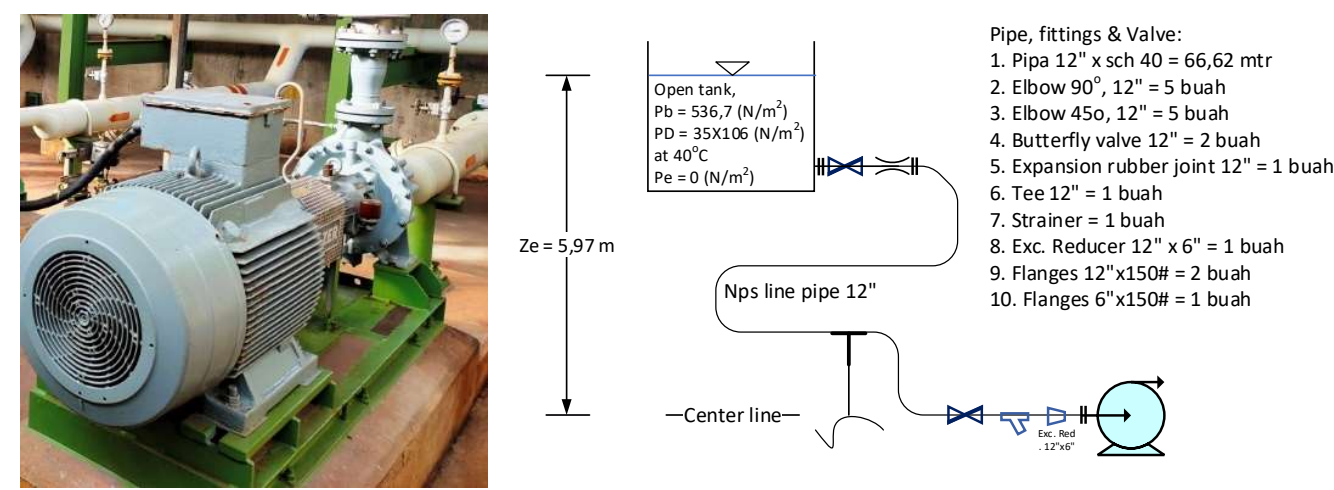

Gambar 3. Foto dan skets Instalasi pompa sentrifugal terpasang

\subsection{Diagram Alir Penelitian}

Berikut diagram alir penelitian, gambar 4.

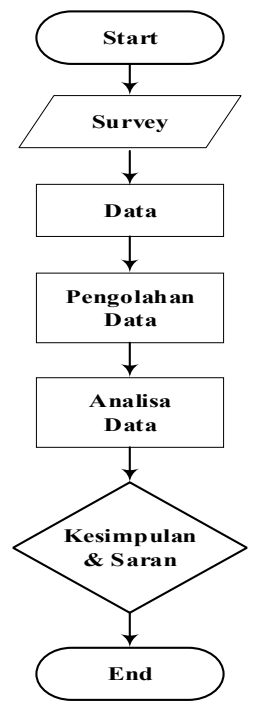

Gambar 4. Diagram alir penelitian

\section{HASIL DAN PEMBAHASAN}

Dari data-data teknis dan data survei lapangan tabel 1 dan gambar 3 dilakukan tahap perhitungan untuk mencari nilai NPSHa sebagai berikut:

\subsection{Menghitung Reynold number (Re) dan kerugian tekanan}

Dari gambar 3 dan table 1 instalasi sistim perpipaan diperoleh data-data sebagai berikut: $\mathrm{L}=66,62 \mathrm{~m} ; \mathrm{D}=0,305 \mathrm{~m}, \mathrm{Q}=0,0778\left(\mathrm{~m}^{3} / \mathrm{s}\right)$; viskositas methanol pada $40^{\circ} \mathrm{C}(313.15 \mathrm{~K})$ dari refrence [3] $\mu=0,00047\left(\mathrm{~N}-\mathrm{s} / \mathrm{m}^{2}\right)$, material pipa A016 Gr.B (commercial steel). 


\section{- Reynold number}

$\mathrm{V}_{12},=\frac{Q}{A}$ di mana $\mathrm{A}=1 / 4 \pi \mathrm{D}^{2}$

$\mathrm{A}=\left(1 / 4 \times 3,14 \times 0,305^{2}\right)=0,073 \mathrm{~m}^{2}$

$\mathrm{V}_{12},=\frac{0,0778}{0,073}=1,07 \mathrm{~m} / \mathrm{s}$

Dari persamaan (7), $\operatorname{Re}=\frac{0,305 \times 774 \times 1,07}{0.00047}=\underline{5,53 \times 10^{5}}$

\section{- Head loss mayor, $\mathbf{h}_{\mathrm{fL}}$ :}

Equivelant roughness pipe $(\varepsilon)$ diperoleh dari gambar 2, untuk material commercial steel $\varepsilon=$ $0,046 \mathrm{~mm}$. sehingga $\varepsilon / \mathrm{D}=0.046 / 305=0,000151(\mathrm{~mm} / \mathrm{mm}), \mathrm{f}=0,00015$ diperoleh dari diagram Moody (gbr.1) berdasarkan nilai Re dan $\varepsilon /$ D. Dari persamaan (5) diperoleh:

$\mathrm{h}_{\mathrm{fL}}=0,0015 \frac{66,62}{0,305}+\frac{1,07^{2}}{2 \times 9,81}=\underline{0,19 \mathrm{~m}}$

- Head loss minor, $\mathbf{h}_{\mathrm{fm}}$ :

Dari data-data gambar 3 dan reference [2] dapat dihitung $\mathrm{h}_{\mathrm{fm}}$ :

Tabel 2. Hasil perhitungan faktor koefisien gesek line pipe 12"

\begin{tabular}{|l|r|r|r|}
\hline Fitting, valve and other & \multicolumn{1}{|c|}{ k } & \multicolumn{1}{|c|}{ Qty } & Total k' \\
\hline 1. Butterfly valve 12"x150\# & 0.525 & 2 & 1.05 \\
\hline 2. Elbow12" L.R 90o & 0.6 & 5 & 3 \\
\hline 3. Elbow 12" 45o & 0.4 & 2 & 0.8 \\
\hline 4. S.O flange 12" x 150\# & 0.78 & 2 & 1.56 \\
\hline 5. Expansion Rubber Joint & 0.85 & 1 & 0.85 \\
\hline 6. Tee 12" x 12" shd 40 & 0.6 & 1 & 0.6 \\
\hline 7. Stariner & 0.8 & 1 & 0.8 \\
\hline 8. excentric reducer 12"x6" & 0.37 & 1 & 0.37 \\
\hline & & $\Sigma \mathrm{k}_{12 "}=$ & 9.03 \\
\hline
\end{tabular}

Dari reference [2] faktor keefisien gesek pipa 6", $\mathrm{k}_{6}{ }^{\prime}=0,78$; kecepatan aliran masuk dari reducer 12"x6" (id 6"sch40 =0,154 m).

$\mathrm{V}_{6},=\frac{Q}{A}$ di mana $\mathrm{A}=1 / 4 \pi \mathrm{D}^{2}$

$\mathrm{A}_{6}=\left(1 / 4 \times 3,14 \times 0,154^{2}\right)=0,019 \mathrm{~m}^{2}$

$\mathrm{V}_{6},=\frac{0,0778}{0,019}=4,19 \mathrm{~m} / \mathrm{s}$

Dari persamaan (8), $\mathrm{h}_{\mathrm{fm}\left(12^{\prime \prime}\right)}=9,03 \frac{1,07^{2}}{2 \times 9,81}=0,523 \mathrm{~m}$ dan $\mathrm{h}_{\mathrm{fm}\left(6^{\prime \prime}\right)}=0,78 \frac{4,19^{2}}{2 \times 9,81}=0,697 \mathrm{~m}$

Jadi $\mathrm{h}_{\mathrm{fm}}=0,523+0,697=\underline{1,22 \mathrm{~m}}$

\subsection{Menghitung NPSHa}

Cairan methanol pada $40{ }^{\circ} \mathrm{C}$ dari tabel reference [3] diperoleh harga tekanan penguapan $\mathrm{P}_{\mathrm{D}}$ $=35 \times 10^{6}\left(\mathrm{~N} / \mathrm{m}^{2}\right)$. Bentuk tangki open maka $\mathrm{P}_{\mathrm{e}}=0\left(\mathrm{~N} / \mathrm{m}^{2}\right)$. Tekanan barometrik atmosfir $\mathrm{P}_{\mathrm{b}}=$ $536,7\left(\mathrm{~N} / \mathrm{m}^{2}\right)$. Head statis total pada instalasi gbr $3 \mathrm{Ze}=5,97 \mathrm{~m}$. Sehingga:

$\mathrm{NPSHa}=5,97+\frac{0+536,7-35000000}{774 \times 9,81}+\frac{4,19^{2}}{2 \times 9,81}-(1,22)=\underline{4,75 \mathrm{~m}}$

\subsection{HargaNPSHr}

Dari pengujian pabrik pembuat pompa (Spesifikasi teknis pompa, tabel 1) diperoleh: $\mathrm{NPSHr}=5 \mathrm{~m}$.

\subsection{Capitation}

Persyaratan agar tidak terjadinya kapitasi pada pomp jika Nilai NPSHa $\geqq$ NPSHr. Dari hasil perhitungan: $\mathrm{NPSHa}=4,75$ dan NPSHr $=5 \mathrm{~m}$ (manufacture) sehingga: 4,75 $<5$ (terjadi kapitasi). 


\subsection{Pembahasan Nilai NPSHa dan NPSHr}

Hasil perhitungan NPSHa lebih kecil dari NPSHr sehingga kondisi ini menyebabkan terjadi kapitasi. Melihat foto kondisi impeller gambar 5 terlihat telah terjadi erosi yaitu tergurasnya permukaan metal yang menyerupai lubang berbentuk kubah cekungan.

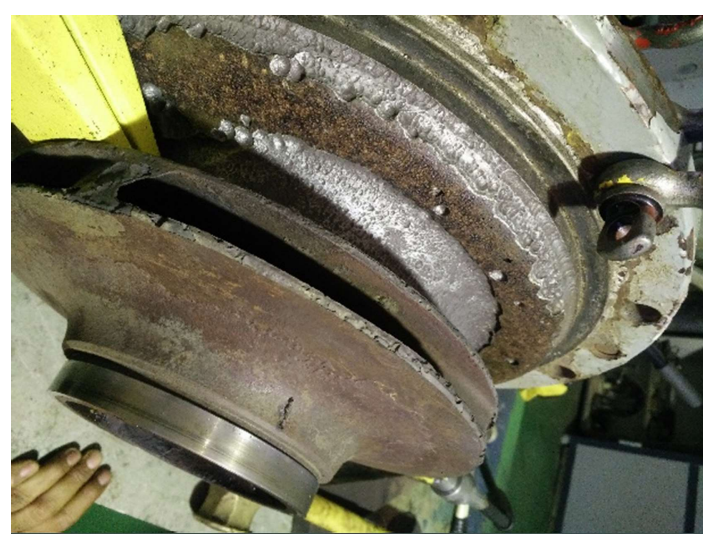

Gambar 5. Foto erosi Impeller pompa (kapitasi). Penulis, 2019

\section{KESIMPULAN}

Dari hasil pengolahan data pada sisi suction sistim perpipaan pompa dan foto dapat disimpulkan sebagai berikut:

a. Nilai NPSHa 4,75 (m) < NPSHr $5(\mathrm{~m})$, nilai ini menggambarkan bahwa persyaratan teradinya proses kapitasi pada pompa yang sedang beroperasi telah terjadi pada ketinggian $\mathrm{Ze}=5,97 \mathrm{~m}$ atau pada level tangki $<45 \%$.

b. Nilai NPSHa $<$ NPSHr terkonfirmasi pada kondisi aktual impeler pompa yaitu tererosinya permukaan diameter luar dan sudu impeller pompa sehingga menurunkan standard performance pompa, gambar 5 .

\section{SARAN}

Hasil nilai NPSHa $<$ NPSHr menggambarkan bahwa sistim perpipaan dimulai dari tangki sampai sisi suction pompa bermasalah sehingga penulis menyarankan sebagai berikut:

a. Perlu dilakukan perhitungan kembali untuk memodifikasi line pipe pada sistem instalasi sisi suction pompa agar tidak terjadi NPSHa $<$ NPSHr (kapitasi)

b. Untuk selanjutnya perlu juga dilakukan penelitian area batas level tangki yang aman agar tidak terjadi NPSHa $<$ NPSHr (kapitasi).

\section{DAFTAR PUSTAKA}

[1] Fritz Dietzel. (2011). Turbin, pompa dan kompresor. Jakarta, Erlangga.

[2] Irving Granet. (1981). Fluid mechanics for engineering technology. Prentice-Hall Inc., Englewood Cliff N.J.

[3] Khalilov Kh.: Viskosität von Flüssigkeiten und gesättigten Dämpfen bei hohen Temperaturen Und Drucken. Zh. Eksp. Teor. Fiz. 9 (1939) 335-34.

[4] Sularso dan Haruo T. (2016). Pompa dan kompresor pemilihan, pemakaian dan pemeliharaan. Edisi keenam, Jakarta, PT. Pradya paramita.

[5] Rahman dan Ikhwansyah. (2012). Simulasi karakteristik bubble sebagai indikasi awal terjadi fenomena kapitasi pompa setrifugal. Jurnal E-Dinamis Teknik Mesin USU, Vol. 1 no. 1.

[6] Ubaedilah. (2016). Analisa kebutuhan jenis dan spesifikasi pompa. Jurnal teknik mesin (JTM) Vol. 5 no. 3. 